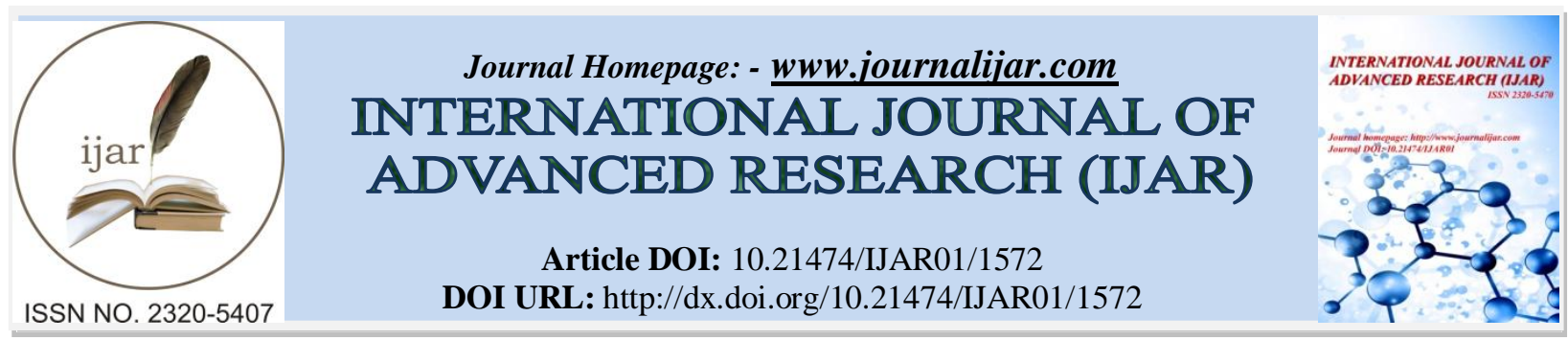

RESEARCH ARTICLE

\title{
FRICTION STIR WELDING OF STAINLESS STEELS - REVIEW.
}

\author{
A. Rajasekhar. \\ Professor, Methodist College of Engineering \& Technology, Abids, Hyderabad, Telangana.-500 001.
}

\section{Manuscript Info}

Manuscript History

Received: 12 July 2016

Final Accepted: 16 August 2016

Published: September 2016

Key words:-

Friction stir welding; stainless steels; microstructure; mechanical properties

\section{Abstract}

After development of tungsten alloys and polycrystalline cubic boron nitride (PCBN) tools, lot of progress is made in FSW of stainless steel. Although some issues remain to be solved, satisfactory welds are produced and weld properties are found suitable for the intended applications. This paper summarizes the progress of research work on Friction stir welding of different types of stainless steels. It covers the research made in the selection of suitable tool materials, optimizing the process parameters such as tool travel speed, rotational speed, tilt angle etc. The influence of Friction stir welding on microstructure and mechanical properties of welds has also been reviewed.

Copy Right, IJAR, 2016,. All rights reserved.

\section{Introduction:-}

Application of high strength, low weight metal alloys are increasing very rapidly in the area of aerospace, aircraft, marine, etc. New technological strategies are required in order to develop welding technology concurrently with the development of new materials. [1]. Both fusion and solid state welding techniques play a major role in welding advanced materials.

Fusion welding involves use of filler materials, shielding gases, and development of high energy density which results wider heat affected zone. The weldments show appreciable modification in the microstructure and properties of weld and heat affected zones, which may result solidification defects like distortion, , lack of penetration, poor fusion, cracks etc. Use of plasma arc and laser beam welding techniques can produce sound welds of thicker materials with narrow heat affected zone [2], however these techniques are not suitable for certain materials such as aluminium, magnesium etc.

The drawbacks in the fusion welding techniques can some extent addressed by solid state welding techniques (e.g. resistance welding, friction welding) in which welding takes place at a temperature lower than the melting point of base metals and also no filler material and / or shielding gases are required. In resistance welding coalescence occurs due to heat generated by contact resistance and applied pressure and hence, it is not suitable for materials having high electrical conductivity (e.g. aluminium, copper). Friction welding employs frictional heat generated when a moving workpiece and a fixed component are forced together in order to obtain the required heat and temperature for weld. However, the application of friction welding is limited by the geometry of the workpieces to be joined.

The above difficulties can successfully overcome by friction stir welding (FSW), a solid state welding process which was developed by the welding institute (TWI) [3] primarily for welding of aluminium and magnesium based alloys. The major advantages of FSW over other welding processes are lower distortion, good dimensional stability, absence of cracking etc. 
Stainless steels are normally classified on a metallurgical basis depending on the composition and metallurgical structure. Hence, recognition is primarily made of martensitic, ferritic, austenitic and duplex phase alloys. These steels have been welded for many years, and the principal welding characteristics of each microstructural type have been well described elsewhere [4].

Literature survey has indicated that FSW was applied successfully to low softening temperature materials such as aluminum, copper lead, zinc, and magnesium alloys [5]. However, Friction stir welding of Stainless steel has not progressed rapidly due to various reasons; the important one is lack of suitable tool materials. Since, Stainless steel is the most widely used material in the engineering application; research is now focused in studying various aspects of Friction stir welding like tool design, rotational speed, welding speed, tool material etc, and their effect on the weld microstructure and properties of stainless steel.

\section{Friction stir welding - principle:-}

In Friction stir welding (FSW) process, coalescence occurs due to thermo-mechanical deformation of workpieces. The temperature developed due to frictional heat exceeds the solidus temperature of workpieces to be joined. The principle of Friction stir welding technique is shown in Figure 1. It consists of a non-consumable rotating tool with a specially designed tool pin and shoulder. Tool pin is plunged into the abutting plates to be joined until the shoulder of the tool touches the upper surface of the material and a downward force is applied to maintain the contact. The tool rotates in the clockwise direction and translates along the joint. Frictional heat generated between tool and workpiece causes the material around the pin to get heated and softened thus forming a solid state joint without melting [6]

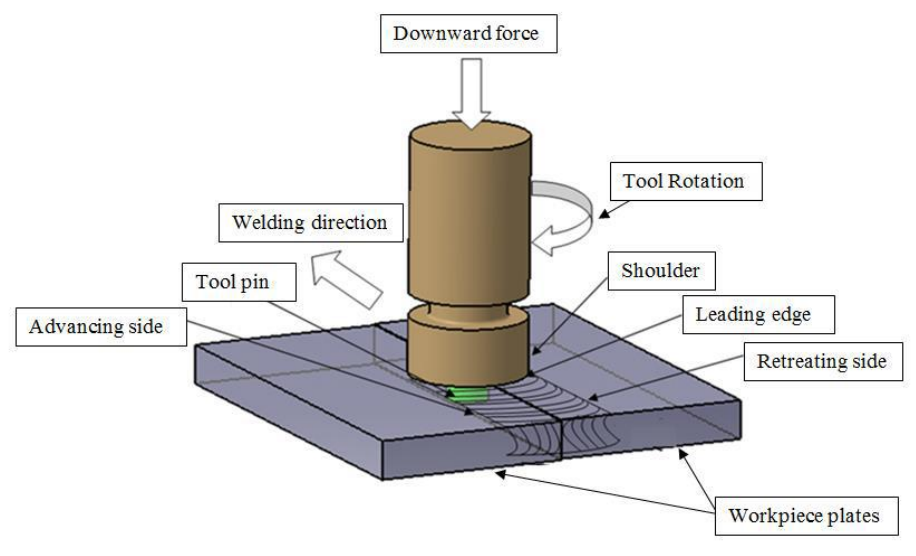

Fig. 1:- Principle of friction stir welding (Backer and Bolmsjo, 2014).

Various micro-structural regions observed in FSW joints are shown in Figure 2. The parent metal region does not undergo any deformation and the microstructure is unaffected by the heat produced in the joint. The heat-affected zone is next to parent metal region and is affected by only heat and there is no plastic deformation takes place in this region; however, the microstructure and mechanical properties are modified by the thermal heat. The next region is thermo-mechanically affected zone which is very close to weld nugget and it experiences lower temperatures and less deformation. Next is nugget zone or stir zone in which severe plastic deformation results due to frictional heat and the material subjected to recrystallization [7].

\section{Microstructure and properties of friction stir welded stainless steels:-}

Austenitic Stainless Steels:-

Reynolds et al. (2003) [8] investigated Friction stir welding of 304L stainless steel using a tungsten alloy tool and experiments were carried out at two different rotational speeds with a constant feed rate. It is evident that equiaxed grains are present in the stir zone with smaller grain size as compare to that of base metal. It is also noticed the existence of narrow bands in stir zone for both rotational speeds. The tensile strength of the weld material was found to be higher than the base metal and exhibited excellent ductility, with elongation to fracture of more than 50\%. Longitudinal residual stresses were found to be nearly matched to the base material yield stress. Furthermore, it is 
concluded that lower energy input due to lower tool rotation would result in lower weld temperature and a fine weld nugget grain size.

When welding 304L stainless steel using PCBN tools under different weld conditions, variations in microstructures were observed by S.H.C. Park et.al. [9]. Under some conditions, rapid formation of sigma phase took place due to the transformation of austenite to delta-ferrite in the stir zone which occurred due to dynamic recrystallization and high strain during the friction stir welding. They also found a banded structure similar to that identified by Reynolds et al. The dark bands were found to be narrow regions of ultrafine grains.

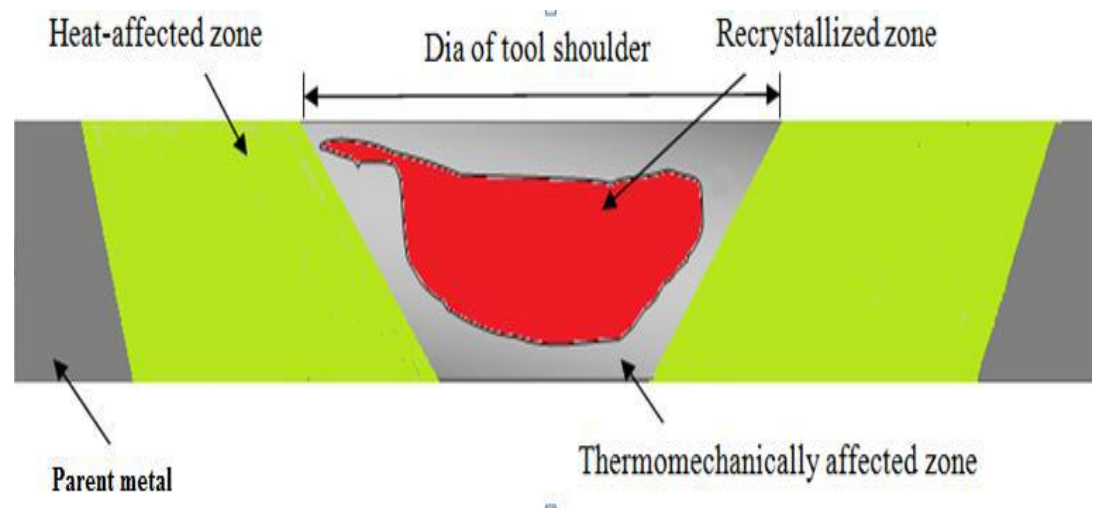

Fig. 2:- Microstructural regions of friction stir welding (Mahoney et al., 1998).

A refined grain structure was also identified in the stir zone of welds produced by friction stir welding of 304 stainless steel welded to low carbon steel. The fine grain structure increased the hardness and tensile strength in the stir zone [10]. Microstructure and mechanical properties of 304 stainless steel welds made by friction stir welding were evaluated by Meran and Kovan [11]. Higher strength of welding was observed when travel speed is $63 \mathrm{~mm} / \mathrm{min}$ and rotational speed is $1000 \mathrm{rpm}$. Friction Stir Welding (FSW) was applied to AISI 304 austenitic stainless steels and the effect of different tool rotational speeds, traverse speeds, compressive tool forces, and tool angles was investigated by C.Meran et.al [12]. It is found that the maximum tensile strength is observed with 950 $\mathrm{rpm}$ rotational speeds and $60 \mathrm{~mm} / \mathrm{min}$ traverse speed, $9 \mathrm{kN}$ compressive tool force, and $1.5^{0}$ tool tilt angle [Fig.3]. Fine-grained microstructures in the welded area and the dark bands in the weld zone were also detected similar to that identified by Reynolds et al.

An increase in hardness of the SZ and TMAZ as compared to base metal was observed in the welds of 2 mm and 6 mm-thick 304 austenitic stainless steel plates [13]. Maximum hardness was located in TMAZ, which is due to high density of dislocations and sub-grains. The microstructure also revealed the presence of ferrite and sigma phase in austenite matrix in the stir zone. C.D. Sorensen et.al., [14] investigated sigma formation in friction stir welding of various stainless steel alloys and hypothesized that sigma formation was a marker for recrystallization in 304L. They also demonstrated that change in welding parameters affected the amount and location of sigma. Brózda and Madej [15] and Kim and et al [16] found that presence of sigma phase in austenitic steel welded joints is the main reason of cracking with its effect of embrittlement. Formation of sigma phase in $304 \mathrm{~L}$ stainless steels was dramatically reduced by modifying the tool design [17]. No sigma has been identified in welds with the new tool.

Sensitization and stress-corrosion cracking (SCC) in 304L stainless steel welds produced by friction stir welding were studied by T.D. Clark [18]. The study reveals that welds analyzed qualified as non-sensitized during an oxalic acid etch test. Increase in corrosion susceptibility away from the surface of the specimen was witnessed in doubleloop electrochemical potentiokinetic reactivation testing. The specimen did not show any increase in SCC susceptibility as compared with the base metal when subjected to U-bend test. 


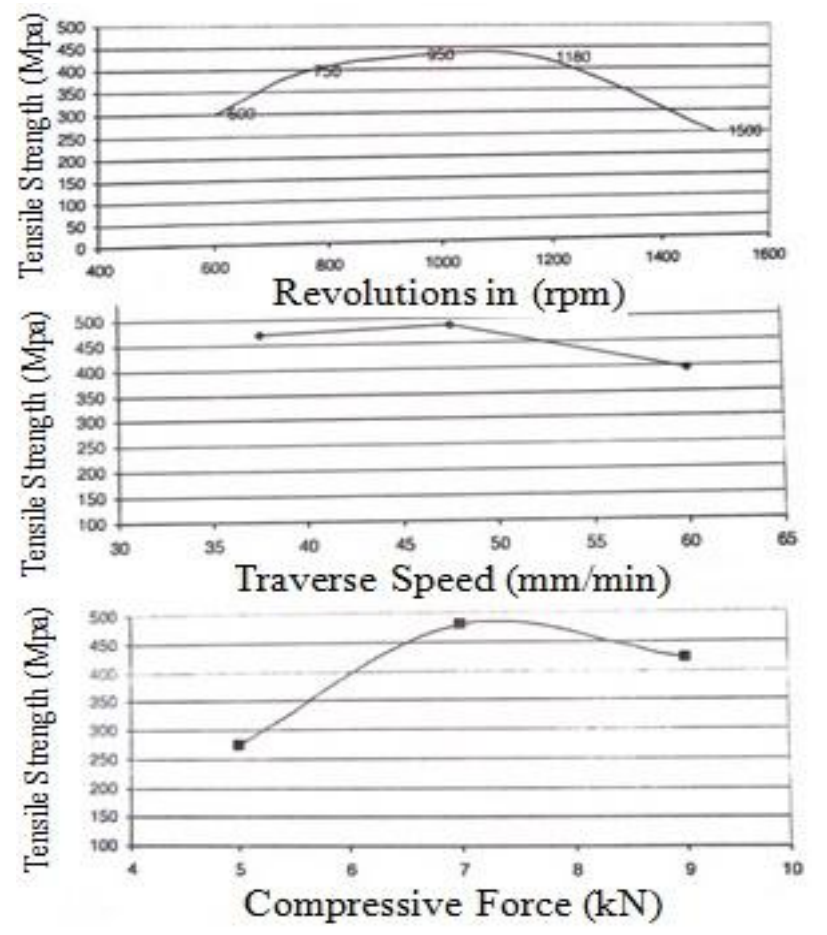

Fig.3:- The influence of the rotational speed, traverse speed and compressive force on the tensile strength of AISI 304 stainless steel produced by FSW. (C.Meran, O.E. Canyurt, 2010)

Welding parameters were optimized in friction stir welding of AISI 316 austenitic stainless steel plates of $4 \mathrm{~mm}$ thick [19]. Defect free welds were produced with rotational speed of $1100 \mathrm{rpm}$ and traverse speed of $8 \mathrm{~mm} / \mathrm{min}$ and welds showed similar tensile strength that of the base material with comparable elongation. Zhou et al. [20] tried to address the keyhole gap problem during friction stir welding of 316L stainless steel using consumable tool bar of similar material. Fine grain microstructure is obtained in stir zone, however void defects are observed at the bottom surface of keyhole.

\section{Ferritic Stainless Steel:-}

Friction stir welding of 409 ferritic stainless steel welded by Polycrystalline Cubic Boron Nitride (PCBN) tool was studied by Cho et al.[21] and found that fine grain microstructure was resulted by dynamic recrystallization. The microstructure and mechanical properties of friction stir welded 409L stainless steel were investigated by Ahn and et al [22] and found that the mechanical properties in the weld were similar to that of the base material (BM). Microstructure and mechanical properties of friction stir welded 409M ferritic stainless steel joints were evaluated by Lakshminarayanan and Balasubramanian [23] and found that properties such as tensile strength, ductility and impact toughness were observed in acceptable limit at a welding speed of $50 \mathrm{~mm} / \mathrm{min}$ and rotation speed of 1000 rpm. Investigations on the microstructure of friction stir welded ferritic stainless steel revealed the presence of bainitic structure in nugget zone and hence increase in hardness of the this zone [24]. Fine grains in nugget zone and TMAZ were observed by Han et al. [25] owing to mechanical stirring and heating.

The influence of tool rotational and traverse speed on friction stir weldability of AISI 430 ferritic stainless steels is studied by Bilgin and Meran [1]. They reported that no sigma phase is found in stir zone and HAZ. A study C.Meran et.al [26] has been taken up to compare the microstructures of AISI 430 ferritic stainless steels resulted by friction stir welding and fusion welding (MIG and TIG) methods. It is found the formation of $\sigma$-phase has not been reported in friction stir welding processes when compared to traditional fusion welding processes. This may be due to lower heat input in friction stir welding. It is also observed that excessive grain growth problem in fusion welding of stainless steels can also be avoided by friction stir welding. 


\section{Duplex Stainless Steel:-}

Mechanical properties of friction stir welded 2507 super duplex stainless steel were evaluated by Sato et al. [27] using CBN tool. The microstructure revealed the refinement of grains of ferrite and austenite and hence resulted an increase in strength and hardness. Tensile fracture occurred between HAZ and TMAZ. The influence of welding speed on microstructure and mechanical properties of friction stir welded duplex stainless steel were studied by Saeid et al [28] and found that microstructure of stir zone consists of equiaxed grains of ferrite and austenite. It is further observed that the grain size decreases with increasing welding speed and the hardness and tensile strength increases when feed rate is increased.

\section{Conclusion:-}

- Friction stir welding has been found to be technically feasible for a wide range of stainless steel alloys.

- Properties of friction stir welds of stainless steels appear to be excellent. In some cases, they exceed the properties of the base metal. They also exceed the properties of welds made from alternative fusion welding processes (TIG and MIG).

- Initial problems with tool material contamination of the weld appear to have been greatly reduced by the development of tool materials like WC and PCBN.

- The process parameters FSW (tool rotation speed, traverse speed, spindle tilt angle and tool geometry) influence the mechanical and metallurgical behavior of welds and hence, they are crucial in producing the sound and defect-free joints.

- A detailed study is required to explore the effect of preheating and filler metal inclusion on mechanical and metallurgical behavior of FSW joints.

- Though some work is in progress on the weldability of austenitic stainless steel by FSW, yet progress is to be made in FSW of other types like Martensitic and duplex stainless steels.

\section{References:-}

1. T.Ueyama // Welding International 24 (2010) 699 and K.Pokhodnya // Welding International 17 (2003) 905

2. Lohwasser and Chen, 2010

3. W.M. Thomas, E.D. Nicholas, J.C. Need-ham, M.G. Murch, P. Templesmith, and C.J. Dawes, International Patent Applica-tion PCT/GB92/02203 and GB Patent Application 9125978.8, 1991

4. Castro, R. \& de Cadenet, J.J., "Welding Metallurgy of Stainless and Heat-Resisiting Steels", pub. by Cambridge University Press, 1974

5. R.Mishra and Z.Ma, Mater Sci Eng R Rep, 50 (1-2), 1-78 (2005)

6. Backer, J. D. \& Bolmsjö, G. (2014).Temperature control of robotic friction stir welding using the thermoelectric effect. Int. J. of Adv. Manuf. Technol., 70, 375-383.

7. Mahoney, M. W.; Rohdes, C. G.; Flintoff, J. G.; Surling,R. A. \& Bingel, W. H. (1998). Properties of frictionstir-welded 7075 T651 aluminum. Metallurgical and Materials Transactions, 29,1955-1964

8. A.P. Reynolds, W. Tang, T. Gnaupel-Herold, and H. Prask, Structure, Proper-ties, and Residual Stress of 304L Stainless Steel Friction Stir Welds, Scr. Mater., Vol 48 (No. 9), May 2003, p 1289-1294

9. S.H.C. Park, Y.S. Sato, H. Kokawa, K. Okamoto, S. Hirano, and M. Inagaki, Rapid Formation of the Sigma Phase in 304 Stainless Steel during Friction Stir Welding, Scr. Mater., Vol 49 (No. 12), Dec 2003, p 1175-1180

10. M. Jafarzadegan, A. Abdollah-zadeh, A.H. Feng, T. Saeid, J. Shen and H. Assadi, Microstructure and Mechanical Properties of a Dissimilar Friction Stir Weld between Austenitic Stainless Steel and Low Carbon Steel, J. Mater. Sci. Technol., 2013, 29(4), 367-372.

11. Meran C, Kovan V, Alptekin A (2007) Friction Stir Welding of AISI 304 austenitic stainless steel, Material Science and Engineering Technology, vol.38, issue 10, pp829-835

12. C.Meran*, O.E. Canyurt "Friction Stir Welding of austenitic stainless steels", Journal of Achievements in Materials and Manufacturing Engineering,Volume 43 Issue 1 November 2010, pp.432-439

13. Kokawa H, Hirano S (2005) Microstructures in friction stir welding of 304 austenitic stainless steel. 56:234236.

14. C.D. Sorensen and T.W. Nelson, Sigma Phase Formation in Friction Stirring of Iron-Nickel-Chromium Alloys, Trends in Welding Research, Proceedings of the Seventh International Conference, ASM International, 2005

15. J. Brózda, J. Madej, Cracking of the mixing chamber caused by sigma phase precipitation in austenitic steel welded joints, Engineering Failure Analysis 15 (2008) 368-377.

16. Y.H. Kim, D.J. Lee, J.C. Byun, K.H. Jung, J.I. Kim, H.J. Lee, Y.T. Shin, S.H. Kim, H.W. Lee. The effect of sigma phases formation depending on $\mathrm{Cr} / \mathrm{Ni}$ equivalent ratio in AISI 316L weldments, Materials and Design 32 
(2011) 330-336.

17. C.B. Owen, "Two-Dimensional Friction Stir Welding Model with Experimental Validation," M.S. thesis, Brigham Young University, Provo, UT, 2006

18. T.D. Clark, "An Analysis of Microstruc-ture and Corrosion Resistance in Under-water Friction Stir Welded 304L Stainless Steel," M.S. thesis, Brigham Young Uni-versity, Provo, UT

19. Manish P. Meshram, Basanth Kumar Kodli, Suhash R. Dey "Friction Stir Welding of Austenitic Stainless Steel by PCBN Tool and Its JointAnalyses", Procedia Materials Science 6 ( 2014 ) 135 - 139

20. Zhou, L.; Zhou, W. L.; Huang, Y. X. \& Feng, J. C. (2015). Interface behavior and mechanical properties of 316L stainless steel filling friction stir welded joints. Int. J. of Adv. Manuf. Technol., 81, 577-583

21. H. Cho, H. N. Han, S. Hong, J. Park, Y. Kwon, S. Kim, and R. J. Steel, "Microstructural analysis of friction stir welded ferritic stainless steel,"Materials Science and Engineering: A, vol. 528, no. 6, pp. 2889-2894, 2011.

22. B.W. Ahn, D.H. Choi, D.J. Kim, S.B. Jung, Microstructures and properties of friction stir welded 409L stainless steel using a Si3N4 tool, Materials Science and Engineering A 532 (2012) 476- 479

23. A.K. Lakshminarayanan and V. Balasubramanian, "An assessment of microstructure, hardness, tensile and impact strength of friction stir welded ferritic stainless steel joints", Materials and Design 31 (2010) 4592-4600

24. Cho, H. H.; Kang, S. H.; Kim, S.H.; Oh, K. H.; Kim, H. J.; Chang, W. S. \& Han, H.N. (2012). Microstructural evolution in friction stir welding of high-strength line pipe steel. Materials \& Design, 34, 258-267

25. Han; Jian; Li, H.; Zhu, Z.; Barbaro, F.; Jiang, L.; Xu, H. \& Ma, L. (2014). Microstructure and mechanical properties of friction stir welded $18 \mathrm{cr}-2$ mo ferritic stainless steel thick plate. Materials \& Design, 63, 238-246

26. C. Meran, M.B. Bilgin, "Fusion and friction stir welding of X6Cr17 stainless steel", Journal of Achievements in Materials and Manufacturing Engineering Volume 61 Issue 2 December 2013, pp.403-410

27. Sato, Y. S.; Yamanoi, H.; Kokawa, H. \& Furuhara, T. (2007). Microstructural evolution of ultrahigh carbon steel during friction stir welding. Scripta Materialia, 57, 557-560

28. Saeid, T; Abdollah-zadeh, A.; Assadi, H. \& MalekGhaini, F. (2008). Effect of friction stir welding speed on the microstructure and mechanical properties of a duplex stainless steel. Materials Science and Engineering, 496, 262-268 